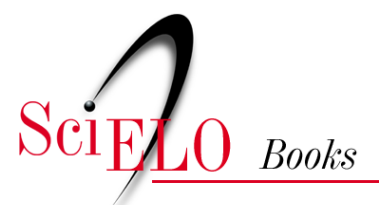

\title{
Histórias do Dr. Leônidas Deane (fevereiro de 1989)
}

\author{
Virgínia Schall
}

\section{SciELO Books / SciELO Livros / SciELO Libros}

SCHALL, V. Histórias do Dr. Leônidas Deane (fevereiro de 1989). In: Contos de Fatos: histórias de Manguinhos [online]. Rio de Janeiro: Editora FIOCRUZ, 2001, pp. 57-66. ISBN: 978-85-7541-614-3. Available from: doi: $10.7476 / 9788575416143.0007$. Also available in ePUB from: http://books.scielo.org/id/hdq6f/epub/schall-9788575416143.epub.

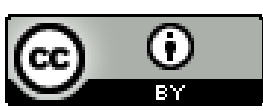

All the contents of this work, except where otherwise noted, is licensed under a Creative Commons Attribution $\underline{4.0 \text { International license. }}$

Todo o conteúdo deste trabalho, exceto quando houver ressalva, é publicado sob a licença Creative Commons Atribição 4.0. 


\title{
Histórias do Dr. Leônidas Deane
}

(fevereiro de 1989)12

\author{
Quando ocorrem, os acasos nos revelama \\ existência, por assim dizer, de analogias ocultas \\ entrefenômenos.
}

Fayga Ostrower

\begin{abstract}
A o reescrever as histórias do Dr. Deane, esboçadas há mais de dez 1 anos, com base no envelhecido caderno de notas onde registrei a nossa conversa, a sua imagem me veio à tona nítida, e eu ainda posso vê-lo e mesmo escutar a sua voz mansa, a cabeça ligeiramente inclinada para frente, numa atitude que transmitia pureza, como bem traduziu Dr. Lobato em texto recentemente publicado. ${ }^{13}$ Seu semblante transbordava bondade. Evocando Neruda, era como se fosse possível escutar o movimento de seu grande coração puro. Recordo a sensação de paz que experimentei em sua sala, no Pavilhão Carlos Chagas, onde a conversa fluiu tranqüila e foi possível observar os seus gestos meticulosos, a sua memória, encontrando rapida-mente, dentre numerosos materiais arquivados, os livros de protocolo das pesquisas e registros
\end{abstract}

\footnotetext{
12 Texto revisado e enriquecido pelo Dr. Ricardo Lourenço de Oliveira, pesquisador do Departamento de Entomologia/IOC.

13 PARAENSE, W. L. 1999. Depoimentos. Fundo Leônidas Deane. Inventário analítico. Departamento de Arquivo e Documentação, Casa de Oswaldo Cruz, Fiocruz, 19-21.
} 
de mais de trinta anos atrás, sobre os quais me falava. Lembro-me também de sua timidez e alegria quase marota, a expressão do menino espontâneo que ele nunca perdeu, manteve-se intacta entre as marcas dos anos em sua face. Essa expressão se iluminou quando elogiei as suas caricaturas, pois já tivera oportunidade de conhecer uma delas na sala da casa do Dr. Luís Rey. Dr. Deane como que desvela a personalidade da pessoa desenhada, e assim estava o Dr. Rey, na caricatura presenteada pelo colega, bem como ele próprio, no auto-retrato, ali na parede da sua sala. Pena que, na época, eu tenha me limitado a registrar apenas as duas primeiras histórias, transcritas a seguir, porque ele falou sobre muito mais. Mas, hoje, ficaram apenas fragmentos, sopros do que poderiam ser outros enredos e fatos, ricos e diversificados como foram os sessenta anos de intensa produção do Dr. Deane.

\section{Duas Vezes a Primeira Vez}

\section{História I}

Esta história se passou em 1953, época em que a leishmaniose visceral ou calazar ${ }^{14}$ era pouco conhecida no Brasil. O conhecimento disponível até então estava todo baseado na forma de calazar do continente europeu (Velho Mundo), ${ }^{15}$ onde a doença, transmitida por mosquitos-palha ou

\footnotetext{
14 A leishmaniose visceral, ou calazar, é hoje uma doença bem conhecida, em que os parasitas (leishmanias) atacam o fígado, baço, medula óssea e orgãos linfóides. O nome calazar vem de kalaazar, denominação dada pelos habitantes de Assam, na Índia, que significa febre negra. No Brasil, atinge principalmente a região Nordeste (da Bahia ao Maranhão), mas há casos em Minas Gerais e no Rio de Janeiro. É transmitida ao homem pela picada de mosquitos (flebotomíneos). Os cães infectados são importante fonte de transmissão, assim como outros animais reservatórios silvestres, como raposas e gambás. (REY, L. Parasitologia. Rio de Janeiro: Guanabara Koogan, 1991)

${ }^{15}$ As expressões Velho Mundo e Novo Mundo são muito utilizadas na literatura, mas, como bem advertiu Dr. Naftale Katz em uma reunião científica, deveríamos deixar de usá-las, por serem carregadas de significados políticos 'incorretos'.
} 
flebotomíneos, infectava cães e humanos. Entretanto, havia evidências de algumas características diferentes da doença no Oriente. Por exemplo: na Índia ela só é transmitida de homem a homem pelos mosquitos flebotomíneos, não havendo outro animal envolvido. Aqui no Brasil, suspeitava-se de animais reservatórios silvestres da doença, mas até então nenhuma descoberta havia sido feita nessa direção. Por vezes eram notificados casos da doença em zonas rurais afastadas; eram casos esporádicos, pontuais, provavelmente relacionados a fontes de infecção silvestre. Centenas de animais silvestres foram capturadas e examinadas por alguns grupos de pesquisa, mas ainda não havia sido encontrado nenhum parasitado com o agente causador da leishmaniose visceral. Tais pesquisas não foram em vão, pois, por meio delas, tornou-se possível descobrir inúmeras, ou melhor, numerosas (já que segundo Ricardo Lourenço, Dr. Deane dizia que "inúmeras só as estrelas do céu, pois não é possível contá-las") espécies novas de parasitas de animais silvestres, mas não o parasita causador da leishmaniose que tanto procuravam.

No decorrer daquele ano, foi noticiado um surto de calazar no Ceará, após outro na Amazônia. Fazendo-se uma analogia com o ciclo do calazar do Velho Mundo, pensou-se logo na transmissão cachorro-flebótomohomem, o que levou o Dr. Deane a se perguntar: por que outros canídeos, como as raposas, por exemplo, não poderiam ser reservatórios da doença? $\mathrm{Na}$ época, Dr. Deane e sua esposa e companheira de trabalho, Dra. Maria Deane, trabalhavam como professores na USP, e foram chamados a visitar o local do surto no Ceará. Corresponderam-se com o médico da região e solicitaram o seu apoio para conseguir raposas, para assim adiantar a pesquisa que lá fariam. Dois meses depois viajaram para o local, onde encontraram uma raposa presa no quintal do médico. Era o mês de dezembro, e eles começaram a se instalar na área. Nas primeiras semanas, contrataram pessoas para trabalhar na captura dos insetos, de raposas, gatos e cachorros e prepararam o ambiente de trabalho. Mal tinham se organizado para iniciar o trabalho e jáera a época de Natal. Os Deane planejavam passar as festas com 
a filha na capital do estado, Fortaleza. Entretanto, antes de viajar, resolveram examinar a raposa presa no quintal do médico. ${ }^{16}$ Foi uma grata surpresa: ela estava infectada! Assim, de primeira, Dr. Deane pôde identificar o primeiro animal reservatório silvestre da leishmaniose visceral encontrado nas Américas.

Naquele dia, telegrafaram imediatamente ao Prof. Samuel Pessoa, chefe da equipe da qual faziam parte. Era uma descoberta inédita na América. Os russos já haviam identificado um reservatório silvestre dois anos antes, era um chacal. Entretanto, publicaram o artigo em russo e a descoberta só foi conhecida quando um pesquisador britânico que vivera na Rússia fez um resumo do trabalho em inglês, o qual foi publicado no Tropical Diseases Bulletin. Dr. Deane destaca o fator sorte: encontrou o parasita no primeiro animal examinado. Em apenas pouco mais de uma semana de permanência no Ceará já cumpria a finalidade do trabalho, descobrindo o que ele próprio e outros procuravam há tanto tempo.

Ao contar a história, Dr. Deane me mostrou o grande livro de protocolo, de capa grossa, cuidadosamente guardado há mais de trinta anos, onde fazia as anotações do seu estudo. Ali havia uma tabela dividida em colunas para registro de diversas informações: data, número do animal, nome vulgar, nome científico, local encontrado etc. A prova do animal número 1 estava lá, registrada com o sinal positivo. Nos olhos do Dr. Deane, a satisfação da descoberta iluminava a página amarelada pelo tempo. Mas uma outra primeira vez ainda estava reservada a ele, como relatado na próxima história.

\section{História II}

A té 1960 predominava a idéia de que a malária humana era transmitida, pelo mosquito, de um ser humano para outro. Entretanto, houve um acidente

\footnotetext{
${ }^{16}$ Na publicação do inventário analítico do Fundo Leônidas Deane (Departamento de Arquivo e Documentação da Casa de Oswaldo Cruz, Fiocruz,1999), encontra-se, na página 73, a foto da raposa citada na história.
} 
em um laboratório de pesquisa dos Estados Unidos, na cidade de Memphis, que gerou uma nova descoberta. ${ }^{17}$ Os cientistas pesquisavam novas drogas que pudessem evitar a penetração dos esporozoítos (forma infectante do parasita da malária) no fígado. Nesses testes, utilizavam-se macacos como modelo experimental. Em Memphis, nunca houvera qualquer registro de malária humana, e foi uma surpresa verificar que alguns auxiliares da pesquisa estavam com malária de macaco, apresentando sintomas iguais aos da malária humana. Foi então confirmada a contaminação no laboratório e a possibilidade da transmissão da doença entre homem e macaco na natureza.

Na ocasião, a Organização Mundial de Saúde (OMS) patrocinava uma grande campanha, composta de estratégias para controle dos mosquitos vetores, os anofelinos transmissores da doença, assim como o tratamento dos doentes, de modo a controlar a fonte de infecção e transmissão. Depois do acidente de Memphis, a OMS lançou programas de estudo da malária de macaco em alguns países, como Malásia, Ceilão, Filipinas, Índia, África e, pouco depois, no Brasil. Dr. Deane, nessa época, fazia um curso na Inglaterra e recebeu um convite do representante da OMS para conduzir os estudos sobre a malária de macaco no Brasil. Respondeu que não sabia se poderia contribuir, pois no Brasil ainda não se havia sequer iniciado qualquer estudo sobre $\mathrm{o}$ assunto.

Ao voltar para o país como professor de parasitologia da Universidade de São Paulo (USP), decidiu que buscaria informações sobre a possibilidade de atender ao pedido da OMS. Pouco depois, dedicado a outras investigações, viu-se de repente beneficiado por um acontecimento casual e inesperado. Certo dia, chegou na universidade um caminhão vindo da

\footnotetext{
17 A malária ou paludismo é uma doença causada por protozoários do gênero Plasmodium, sendo que quatro espécies parasitam o homem, cerca de 22 infectam macacos e cinqüienta infectam aves ou répteis. O protozoário é injetado na circulação por mosquitos do gênero Anopheles. Há desde formas benignas até formas graves e fatais de malária, que já atingiu até 350 milhões de pessoas nas primeiras décadas deste século. (REY, L. Parasitologia. Rio de Janeiro: Guanabara Koogan, 1991: 286-336)
} 
Serra da Cantareira. Estavam entregando madeiras encomendadas. Dr. Deane foi chamado por um funcionário que perguntou se ele teria interesse em ficar com um macaco que o caminhoneiro havia recolhido, pois o encontrara caído à beira da estrada. Dr. Deane recebeu o macaco, um guariba ou bugio, do qual recolheu sangue; horas depois, ao examiná-lo, encontrou o parasita da malária no primeiro campo da primeira lâmina. Entusiasmado, marcou com diamante a lâmina e foi examinar as outras seis já preparadas. Não encontrou mais nenhum parasita. Entretanto, o exemplar único observado foi suficiente para motivá-lo a pesquisar o ciclo de transmissão e o levou novamente a ser o primeiro pesquisador a descobrir o vetor da malária de macaco nas Américas, como a seguir relatado.

No mês seguinte, realizou-se em São Paulo um congresso internacional ao qual compareceu o representante da OMS. Dessa vez Dr. Deane não titubeou, aceitou o convite e passou a desenvolver o projeto. Passaram-se nove anos e o Dr. Deane examinou 110 florestas, da Amazônia (Amaṕ, Acre, Amazonas) ao Rio Grande do Sul. Estimou que 20\% dos macacos tinham malária. Exceto no Nordeste, área mais seca, todas as florestas brasileiras tinham malária. Dr. Deane e sua equipe encontraram malária em 25 diferentes espécies de macaco. Mantinha, o tempo todo, o objetivo de descobrir o que transmitia malária aos macacos. Observou, então, que havia uma relação entre a transmissão da malária de macacos e a distribuição vertical de diferentes mosquitos: as espécies que picam perto do solo diferem daquelas das copas das árvores. Fizeram capturas no nível do solo e nas copas. Provavelmente os transmissores para os macacos estariam nas copas, já que este é um animal arborícola. Certamente seria um anofelino, pois este é o úniço gênero que transmite a malária de mamíferos. A malária de réptil, por sua vez, é transmitida por mosquitos culicíneos ou flebotomíneos. $\mathrm{E}$, assim, descobriram um mosquito encontrado quase que somente na copa das árvores. Era um anofelino que só habitava essa altura, sendo muito raro encontrá-lo no solo naquela região. Esta mesma espécie de mosquito é encontrada em outros lugares e no litoral, voando próximo 
ao solo. Em alguns locais, dependendo da uniformidade da umidade e da temperatura, é indiferente a altura em que voam; em outras áreas, com variações climáticas mais acentuadas, a altura do vôo é relevante.

Essa pesquisa foi realizada na Serra da Cantareira, em São Paulo. Para atrair os mosquitos e capturá-los, os pesquisadores, orientados pelo Dr. Deane, penduravam na árvore uma gaiola com um macaco sadio. Dessa forma, encontraram o Anopheles cruzi (transmissor da malária humana no extremo Sul do Brasil e nos vales montanhosos de influência da Mata Atlântica, no Sudeste) dentro da gaiola com o macaco. Na mesma ocasião, foram coletados nessa armadilha dois mosquitos infectados. Passados alguns dias, o sangue do macaco que servia de isca apareceu infectado com as duas espécies de malária de macaco existentes no continente americano (Novo Mundo). Assim, descobria-se pela primeira vez o vetor da malária de macacos nas Américas. Dr. Deane fez muitas outras pesquisas; numa de suas últimas publicações, ${ }^{18}$ de 1992, pode-se encontrar uma revisão e dados atualizados sobre o seu trabalho.

Dr. Deane contou ainda o caso interessante de um guarda florestal da Serra da Cantareira, em São Paulo, que exemplifica como o homem pode contrair a malária de macaco em certas condições especiais. Esse guarda, Antônio Cassalho, um homem quase analfabeto mas com um espírito de colaboração inigualável, era entusiasmado pelo trabalho, subia nas árvores até de bota e quepe. Capturava mosquitos no próprio corpo, deixando que eles o sugassem. Dr. Deane recomendava que ele tomasse preventivo, mas ele retrucava: "Mas isso dificulta a sua experiência", e não tomava. Era filho de um outro guarda florestal da mesma serra e, lá, ninguém nunca tivera malária e nem sabiam o que era esta doença. Certa feita, Antônio apareceu com a malária de macaco. Pegou a malária simiana porque subia nas árvores sem qualquer proteção, confirmando que, ali, os mosquitos

${ }^{18}$ DEANE, L. Memórias do Instituto Oswaldo Cruz, 87 (III):1-20, 1992. 
picavam na altura da copa e que a transmissão da infecção estava restrita a esse estrato da floresta. Dr. Deane o levou para o Hospital das Clínicas para tratar a sua malária com os medicamentos usados na malária humana. O guarda chegou a sugerir que não o tratassem para que descobrissem como a malária de macaco evoluiria num humano. Após cinco dias, a malária dele desapareceu espontaneamente. Por sua coragem, foi possível demonstrar que a malária de macaco pode ser transmitida naturalmente ao homem e que cura espontaneamente. 


\section{Dr. Leônidas Deane ${ }^{19}$}

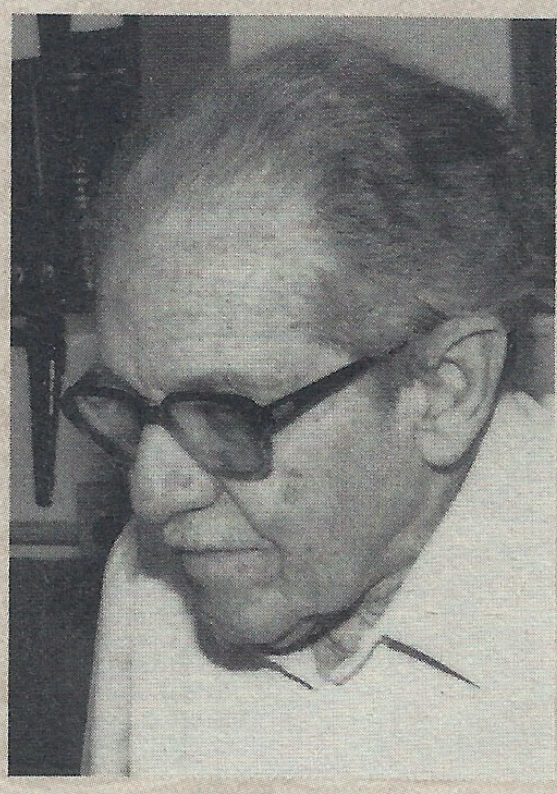

Dr. Leônidas de Mello Deane nasceu em 1914, na cidade de Belém do Pará, onde se formou em medicina pela Faculdade de Medicina e Cirurgia do Pará, em 1935. Já no ano seguinte tornava-se professor de microbiologia daquela escola. Na mesma ocasião, começou a trabalhar como parasitologista do atual Instituto Evandro Chagas (na época, Instituto de Patologia Experimental do Norte), onde ficou até 1939 e, depois, de 1942 a 1949. Na primeira fase, fez estudos sobre leishmaniose visceral, dentre outras endemias, integrando a equipe orientada por Evandro Chagas. Ainda como parasitologista do Serviço Especial de Saúde Pública, no ceará, participou do combate ao mosquito Anopheles gambiae, transmissor da malária. Casouse em 1940 com a pesquisadora Dra. Maria José von Paumgartten Deane, formando com ela um casal de cientistas muito produtivo. É exemplar a colaboração de ambos à saúde pública no Brasil. Fez mestrado na Universidade John Jopkins, EUA, e cursos de parasitologia e entomologia na universidade de Michigan, entre 1944 e 1955. Foi chefe do Laboratório de Entomologia do Instituto de Malariologia em Belém, PA, de 1946 a 1953, ano em que se transferiu para São Paulo a convite do Prof. Samuel Pessoa, lá

\footnotetext{
${ }^{19}$ Resumo da biografia incluída na publicação Fundo Leônidas Deane: inventário analítico, do Departamento de Arquivo e Documentação, Casa de Oswaldo Cruz, Fiocruz, 1999: 27-29.
} 
permanecendo até 1970. Foi professor na Universidade de Carabobo, Venezuela, de 1976 a 1979, para onde foi com a família na época da ditadura militar. Em 1980, com a anistia, voltou ao Brasil. Convidado pelo Dr. José Rodrigues Coura, então vice-presidente de Pesquisa da Fiocruz, a chefiar o Departamento de Entomologia do IOC, lá permaneceu até 1993, quando veio a falecer, aos 79 anos. É notória sua contribuição para a epidemiologia e o controle das doenças tropicais brasileiras - malária, leishmaniose, filariose e doença de Chagas -, assim como para a formação de novos pesquisadores e para a biologia em geral. Descreveu diversas novas espécies de mosquitos e parasitas. Foi também exímio caricaturista e desenhista, ilustrando ele mesmo os seus trabalhos científicos. Participou de vários comitês nacionais e internacionais como perito em parasitologia e recebeu numerosos prêmios. Tanto ele quanto a Dra. Deane foram homenageados pela Fiocruz com a criação do centro de Pesquisas Leônidas \& Maria Deane, em Manaus, em 1994, e por vários pesquisadores brasileiros e estrangeiros que nomearam diversas novas espécies de insetos e protozoários com o sobrenome Deane. 